\title{
(6) OPEN ACCESS \\ Cystatin C as a predictive marker of renal dysfunction and mid-term outcomes following off-pump coronary artery bypass grafting
}

\author{
Seung Hyun Lee, Young-Nam Youn, Hyun Chel Choo, Sak Lee, Kyung-Jong Yoo
}

- Additional material is published online only. To view please visit the journal online (http://dx.doi.org/10.1136/ heartjnl-2015-307986).

Division of Thoracic and Cardiovascular Surgery, Severance Cardiovascular Hospital, Yonsei University, College of Medicine, Yonse University Health System, Seoul, Republic of Korea

\section{Correspondence to} Professor Young-Nam Youn, Severance Cardiovascular Hospital, Yonsei University Health System, 250 Seongsanno, Seodaemun-gu, Seoul, 03722, Republic of Korea; ynyoun@yuhs.ac

Received 14 April 2015 Revised 2 July 2015 Accepted 3 July 2015 Published Online First 27 July 2015

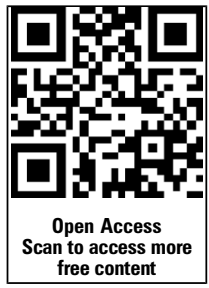

CrossMark

To cite: Lee SH, Youn Y-N, Choo HC, et al. Heart 2015;101:1562-1568.

\section{ABSTRACT \\ Objective To determine whether plasma cystatin $C$ and creatinine levels after isolated off-pump coronary artery bypass grafting $(O P C A B)$ are predictive of postoperative renal dysfunction and clinical outcomes.}

Methods Between January 2008 and December 2013, 1033 who underwent isolated OPCAB were recruited. The patients were divided into three groups according to the preoperative level of cystatin C: low $(0.83 \mathrm{mg} / \mathrm{L}>)$, mid (0.83-1.13 mg/L) and high (1.13 mg/L<). The endpoints of all-cause mortality and major adverse cerebrovascular and cardiovascular events were compared among three groups using the Kaplan-Meier method. The predictive power of cystatin $C$ was compared with creatinine using receiver operating curves. Results Follow-up was complete in all of the included patients at a mean of $2.9 \pm 1.5$ years. Within the followup period, 9 early (30-day mortality) and 46 late deaths occurred. The 30 -day mortality was zero, four (44\%), and five $(56 \%)$ cases in low, mid and high groups, respectively $(p=0.03)$. The cut-off value of cystatin $C$ for renal dysfunction prediction was approximately 1.04 (mg/L, $\mathrm{p}<0.001)$, and cystatin C showed greater predictive power than creatinine for renal dysfunction (area under the curve $=0.73$ vs $0.65 ; p=0.01$ ). One-year and five-year overall survival in low, mid and high groups were $99.2 \%, 98.9 \%$ and $94.3 \%$, and $97.9 \%$, $97.3 \%$ and $86.3 \%$, respectively (low vs high, $\mathrm{p}=0.01$ ). Conclusions Cystatin $\mathrm{C}$ is a stronger predictor of postoperative renal dysfunction than serum creatinine, and its level is directly correlated with mid-term OPCAB adverse results.

\section{INTRODUCTION}

Postoperative renal dysfunction affects $1-5 \%$ of patients who have undergone cardiac surgery and remains a leading cause of morbidity and mortality in this patient group. ${ }^{1-3}$ Regardless of the various pathophysiologies of renal injury, its two main aetiologies are as follows: perioperative renal hypoperfusion and the presence of endogenous and exogenous nephrotoxins (free radicals, pro-inflammatory cytokines, circulating catecholamines, anaesthetic agents and contrast media). These factors can induce glomerular and tubular injury, especially in the presence of comorbidities (eg, preoperative renal dysfunction, diabetes mellitus, impaired left ventricular function and advanced age). Because of the key role renal dysfunction plays in predicting the outcomes of cardiac surgery and the patient's prognosis, it is important that surgeons have a realistic preoperative understanding of renal dysfunction risk factors. One of the most important determinants for AKI is the patient's preoperative renal reserve determined by preoperative assessment of kidney function. $^{2} \quad 4^{5}$ Serum creatinine concentration is the most useful and widely used determinant for renal dysfunction.

Although serum creatinine concentration remains the clinical standard for renal dysfunction diagnosis, it may not be ideal because creatinine is an inaccurate measure of glomerular filtration. A small proportion of creatinine is secreted in urine without being filtered, and serum creatinine levels are dependent on its generation from muscle mass, which may be reduced in the postoperative setting. ${ }^{6}$ In recent studies, serum cystatin $\mathrm{C}$ has been featured as an easily measurable marker of kidney function that is less influenced by nonglomerular filtration rate (GFR) determinants, such as muscle mass, and it is eliminated solely by glomerular filtration. ${ }^{78}$ However, few studies have evaluated the predictive power of cystatin $\mathrm{C}$ in adult cardiac surgery, particularly procedures with off-pump coronary bypass (OPCAB), although the postoperative cystatin $\mathrm{C}$ level did show a positive correlation with surgical outcomes in paediatric cardiac surgery patients. ${ }^{8}$

The aim of this study was determine whether cystatin $\mathrm{C}$ and creatinine are predictive of renal dysfunction and evaluate their prognostic value for clinical outcomes after OPCAB.

\section{METHODS}

Study population

A total of 1418 consecutive patients undergoing isolated $\mathrm{OPCAB}$ at Severance Cardiovascular Hospital, Yonsei University Health System, from January 2008 to December 2013 were identified retrospectively. Of these patients, 385 were excluded; in 210 of these patients, the serum cystatin C level had not been evaluated preoperatively, and 175 met the following exclusion criteria: emergency operation, preoperative serum creatinine $\geq 3.0 \mathrm{mg} / \mathrm{dL}$ (or on dialysis) surgery under cardiopulmonary bypass or concomitant valve surgery, missing or incomplete record case. A total of 1033 who underwent isolated OPCAB were recruited finally. Blood samples were collected preoperatively and on the first, second, fourth and seventh days postoperatively to measure serum cystatin $\mathrm{C}$ and creatinine in all of the included patients. 
Previous studies for evaluating the cystatin $\mathrm{C}$ as a predictor of renal function in various situations showed the guiding and reference value. Cystatin C level $1.13(\mathrm{mg} / \mathrm{L})$ is a usual value for the worst categorisation that represent the $20 \%$ of participants with the highest cystatin $\mathrm{C}$ level and $0.83(\mathrm{mg} / \mathrm{L})$ represented $20 \%$ of participants with the lowest cystatin C level. ${ }^{9}{ }^{10}$ So we categorised our cohort into three groups according to the preoperative serum cystatin $\mathrm{C}$ level, defined as low $(<0.83 \mathrm{mg} / \mathrm{L})$, mid $(0.83-1.13 \mathrm{mg} / \mathrm{L})$ and high $(>1.13 \mathrm{mg} / \mathrm{L})$. 'High' represented the $20 \%$ of participants with the highest cystatin C level and the highest creatinine level. All baseline and clinical characteristics were obtained from the medical record of patients.

\section{Operative technique}

The operative technique and graft strategy have been previously described. ${ }^{11}$ Briefly, the operation was performed through a full sternotomy incision or minimal incision through the left fifth intercostal space, and the left internal mammary artery was harvested in a semi-skeletonised fashion. The second choice of graft was the radial artery, which was harvested with a Harmonic scalpel (Ethicon Endosurgery, Cincinnati, Ohio, USA). The right internal mammary artery, saphenous vein or right gastroepiploic artery was also harvested, if necessary. Heparin $(0.7-1.0 \mathrm{mg} / \mathrm{kg}$ ) was administered to achieve a target activated clotting time $(\geq 300 \mathrm{~s})$ before ligation of the distal internal mammary artery. Target arteries were stabilised with a tissue stabiliser and heart positioner. During anastomosis, blood was removed from the arteriotomy sites with a misted carbon dioxide blower, and the area was irrigated with warm saline. After surgery, the patients were transferred to the intensive care unit and managed as usual.

\section{Definition of renal dysfunction and transformation formula of estimation of GFR}

Renal dysfunction is defined as any of the following: (1) an increase in serum creatinine $\geq 0.3 \mathrm{mg} / \mathrm{dL}(\geq 26.5 \mu \mathrm{mol} / \mathrm{L})$ within
$48 \mathrm{~h}$, (2) an increase in serum creatinine to $\geq 1.5$ times baseline, which is known or presumed to have occurred within the prior 7 days, and (3) a urine volume $<0.5 \mathrm{~mL} / \mathrm{kg} / \mathrm{h}$ for 6 h. $^{12}$ We used our hospital transformation formula of estimated GFR as follows: (1) creatinine-based estimation of $\mathrm{GFR}=175 \times(\mathrm{Scr})^{-1.154} \times(\text { Age })^{-0.203} \times(0.742$ if female $) ;$ and (2) cystatin-based estimation of $\mathrm{GFR}=84.69 \times$ cystatin $\mathrm{C}$ $(\mathrm{mg} / \mathrm{L})^{-1.680} \times 1.384 *$ (* for children $<14$ years).

\section{Statistical analysis}

Categorical variables, presented as frequencies and percentages, were compared using the $\chi^{2}$ test. Continuous variables, expressed as the mean \pm SD or the median with a range as appropriate, were compared using Student's t test. The KaplanMeier method was used to delineate the overall survival rate and mortality and major adverse cerebrovascular and cardiovascular events (MACCEs), and the log-rank test was used to compare the differences in the rates between low, mid and high groups.

The incidences of renal dysfunction were calculated by the quintile of each of the two kidney function measures. We compared the strength and independence of the association between each kidney function measure and the renal dysfunction across the best, intermediate and worst groups. We used multivariate logistic regression analyses to determine the associations of kidney function categories according to cystatin $\mathrm{C}$ with major adverse cerebrovascular and cardiovascular events MACCEs. The models were adjusted for demographics, comorbid conditions and procedural variables, as listed above.

To evaluate the predictability of each kidney function test (cystatin $\mathrm{C}$ level and creatinine level) on risk discrimination, we constructed receiver operating characteristic curves and calculated the $\mathrm{C}$ statistic (area under the curve (AUC)). The $\mathrm{C}$ statistic was compared for each variable to determine the predictability of MACCEs and renal complications. All reported $\mathrm{p}$ values were two-sided, and a value of $\mathrm{p}<0.05$ was considered statistically significant. SPSS V.18.0 (IBM Corp., Armonk, New York, USA)

Table 1 Baseline characteristics and operative data

\begin{tabular}{|c|c|c|c|c|}
\hline Variables* & Low $(\mathrm{n}=278)(0.83 \mathrm{mg} / \mathrm{L}>)$ & $\operatorname{Mid}(n=519)(0.83-1.13 \mathrm{mg} / \mathrm{L})$ & High $(n=236)(1.13 \mathrm{mg} / \mathrm{L}<)$ & $\mathrm{p}$ Value \\
\hline Age (years) & $60.9 \pm 9.6$ & $65.5 \pm 8.3$ & $69.8 \pm 9.1$ & 0.01 \\
\hline Females (n, \%) & $62(24 \%)$ & $109(24 \%)$ & $56(28 \%)$ & 0.53 \\
\hline HTN $(n, \%)$ & $163(64 \%)$ & $329(73 \%)$ & 167 (84\%) & 0.01 \\
\hline $\mathrm{DM}(\mathrm{n}, \%)$ & $90(35 \%)$ & $177(40 \%)$ & $106(54 \%)$ & 0.01 \\
\hline Dyslipidemia (n, \%) & $162(64 \%)$ & $178(40 \%)$ & $66(34 \%)$ & 0.21 \\
\hline CVA $(n, \%)$ & $16(6 \%)$ & $33(7 \%)$ & $34(17 \%)$ & 0.01 \\
\hline $\operatorname{COPD}(n, \%)$ & $3(1 \%)$ & $9(2 \%)$ & $10(5 \%)$ & 0.02 \\
\hline PAOD $(n, \%)$ & $13(5 \%)$ & $26(6 \%)$ & $30(15 \%)$ & 0.01 \\
\hline EuroSCORE & $3.2 \pm 2.3$ & $3.9 \pm 2.3$ & $5.7 \pm 3.8$ & 0.01 \\
\hline NYHA $(3 \leq n, \%)$ & $47(17 \%)$ & $98(19 \%)$ & $72(31 \%)$ & \\
\hline LVEF (\%) & $58.5 \pm 13.0$ & $57.3 \pm 14.7$ & $51.5 \pm 14.7$ & 0.01 \\
\hline LVESD (mm) & $35 \pm 7.5$ & $35.8 \pm 8.3$ & $37.4 \pm 8.7$ & 0.01 \\
\hline LVEDD (mm) & $50.5 \pm 6.6$ & $50.7 \pm 7.3$ & $51.3 \pm 8.2$ & 0.57 \\
\hline Distal anastomosis (n) & $3.2 \pm 0.9$ & $3.2 \pm 0.8$ & $3.6 \pm 0.8$ & 0.52 \\
\hline LIMA usage $(n, \%)$ & $246(96 \%)$ & $438(98 \%)$ & $195(99 \%)$ & 0.76 \\
\hline C.R. $(n, \%)$ & $230(90 \%)$ & $413(92 \%)$ & $180(91 \%)$ & 0.81 \\
\hline Operation time (min) & $229.4 \pm 41.3$ & $235.6 \pm 46.3$ & $232.3 \pm 42.8$ & 0.21 \\
\hline
\end{tabular}

* Data for continuous variables are shown as mean \pm SD (range) and data for categorical variables as number (\%).

CR, complete revascularisation; COPD, chronic obstructive pulmonary disease; CVA, cerebrovascular accident; DM, diabetes mellitus; EuroSCORE, European System for Cardiac Operative Risk Evaluation; HTN, hypertension; LIMA, left internal mammary artery; LVEDD, LV end-diastolic dimension; LVESD, LV end-systolic dimension; NYHA, New York Heart Association; PAOD, peripheral artery occlusive disease. 
Table 2 Operative outcomes after stratification for cystatin C level

\begin{tabular}{|c|c|c|c|c|}
\hline & Low $(n=278)$ & $\operatorname{Mid}(n=519)$ & High $(n=236)$ & p Value \\
\hline \multicolumn{5}{|l|}{ Early result ( 30 days $>$ ) } \\
\hline Wound complications ( $\mathrm{n}, \%)$ & $3(1.08)$ & $12(2.31)$ & $4(1.69)$ & 0.43 \\
\hline Neurological complications (n, \%) & $4(1.44)$ & $6(1.16)$ & $2(0.84)$ & 0.85 \\
\hline Delayed ventilation $(48 \mathrm{~h}<, \mathrm{n}, \%)$ & $5(1.80)$ & $33(6.36)$ & $20(8.47)$ & 0.01 \\
\hline Renal dysfunction $(n, \%)$ & $15(5.04)$ & $44(75.88)$ & $72(30.5)$ & 0.01 \\
\hline Mortality (30 days) & $0(0)$ & $4(0.8)$ & $5(2.1)$ & 0.03 \\
\hline
\end{tabular}

and MedCalc (MedCalc Software, Ostend, Belgium) were used for the statistical analyses.

\section{RESULTS}

Baseline characteristics and in-hospital outcomes

The baseline demographic, echocardiography and other preoperative parameters are detailed in table 1. The baseline characteristics were compared across the three groups. In summary, patients in the high group tended to be older. In addition, diabetes mellitus, hypertension, cerebrovascular attacks and peripheral artery obstructive diseases were more common in the high group. However, the number of distal anastomosis (low group 3.2 \pm 0.9 , mid group $3.2 \pm 0.8$ and high group 3.1 \pm 0.8 , $\mathrm{p}=0.52$ ) and length of the operation in minutes (low group $229.4 \pm 41.3$, mid group $235.6 \pm 46.3$ and high group 232.3 $\pm 42.8, \mathrm{p}=0.21$ ) were not significantly different among groups.

\section{Clinical events: morbidity and mortality outcomes}

We compared the clinical outcomes among the three groups defined by cystatin C levels. Follow-up was complete in all of the included patients at a mean of $35.2 \pm 18.1$ months (IQR 22.9-51.0 months), during which time there were 9 early (30-day mortality) and 46 late deaths. The 30-day mortality was zero, four (44\%) and five (56\%) cases in the low, mid and high groups, respectively $(\mathrm{p}=0.034)$ (table 2$)$.

In our evaluation of the sensitivity of each kidney function test (cystatin $\mathrm{C}$ level and creatinine level) on risk discrimination, the cut-off value of cystatin $C$ for predicting mortality was 1.04 (figure 1). Cystatin $\mathrm{C}$ proved to be a more powerful predictor for postoperative renal dysfunction than serum creatinine (figure 2). We found that converting the estimated GFR (eGFR) produced a value more sensitive for predicting adverse renal dysfunction. Both eGFR converted from the cystatin $\mathrm{C}$ and creatinine increased the AUC value rather than pre-converting value, and of these two, the most sensitive predictor was the cystatin-based eGFR (AUC $=0.733$, CI 0.70 to 0.760). However, cystatin was not a statistically significant predictor of mortality (AUC 0.73 vs $0.70, p=0.47$ ) or MACCEs (AUC 0.61 vs 0.62 , $\mathrm{p}=0.91$ ) compared with creatinine (figure 3 ).

The overall survival rates at 1,3 and 5 years were 99\%, 98\% and $97 \%$ in the low group, 98\%, 97\% and $97 \%$ in the mid group, and $94 \%, 86 \%$ and $86 \%$ in the high group log-rank test, low vs high group, $\mathrm{p}<0.001$, respectively, using the KaplanMeier method. The freedom from MACCEs showed result similar to that of the overall survival rate between the low and high groups (log-rank test, $\mathrm{p}<0.001)$ (figure 4).

Univariate and multivariate Cox regression analyses were used to assess the predictors of mortality and other adverse events. After adjustment for preoperative baseline characteristics and age, category high group (cystatin $\mathrm{C}>1.13 \mathrm{mg} / \mathrm{L}$ ) was independently related to mortality and MACCEs. The odds ratio for mortality according to age and across all groups was $1.10(95 \%$ CI 1.03 to $1.17, \mathrm{p}<0.001)$ and 0.35 (95\% CI 0.14 to 0.83 , $\mathrm{p}=0.02$ ) (table 3 ), respectively. We also found that the cystatinbased eGFR and plasma cystatin C category (high group) were statistically significant factors for predicting postoperative renal dysfunction (table 4).

\section{DISCUSSION}

Postoperative renal dysfunction is one of the critical complications of cardiac surgery. Not only does renal dysfunction lead to an increased in-hospital mortality risk, but it also predisposes the patient to long-term mortality risk, even among those who appear to recover from the renal dysfunction. ${ }^{13}{ }^{14}$ However, little is known about the sensitivity and specificity of renal dysfunction predictive factors. In clinical practice, serum creatinine is the most commonly used parameter for the assessment of renal function, although it has many limitations. It has a low sensitivity, and its assay is influenced by numerous factors, resulting in wide inter-individual variability.

Cystatin $\mathrm{C}$ is a cysteine protease inhibitor produced by all nucleated cells. It is a non-glycosylated low-molecular-weight plasma protein $(13 \mathrm{kDa}) .{ }^{15}$ As glomerular filtration is the only

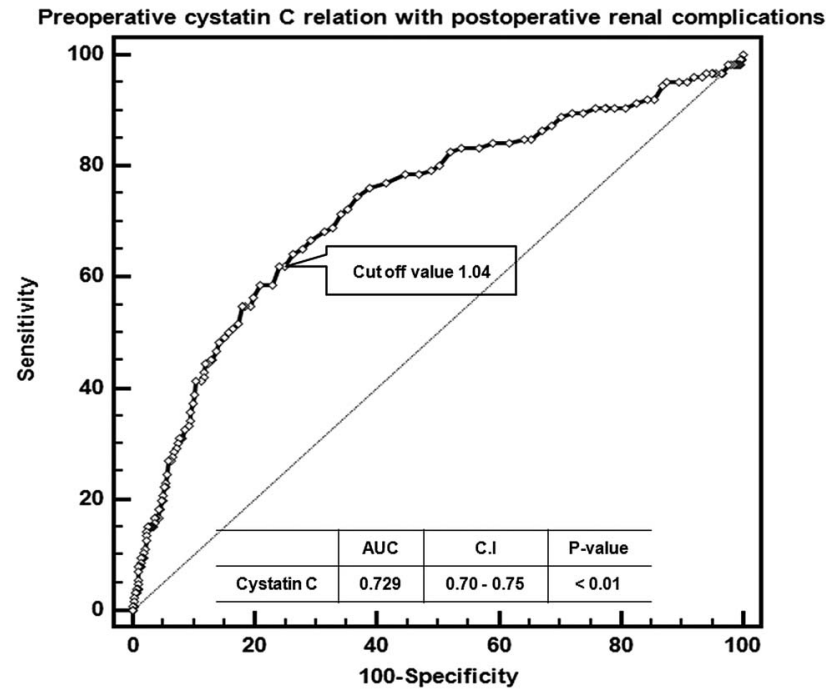

Figure 1 Receiver operating characteristic (ROC) curve of cystatin C and cut-off value for prediction of renal dysfunction. ROC plots of serum cystatin $C$ demonstrated the area under the curve (AUC) for renal dysfunction ( $A U C=0.73, \mathrm{Cl} 0.70$ to $0.75, \mathrm{p}<0.001$ ). The cut-off value for maximising AUC (or the Yoden index) of AKI was $1.04 \mathrm{mg} / \mathrm{L}$. Renal dysfunction is defined as any of the following: (1) an increase in serum creatinine $\geq 0.3 \mathrm{mg} / \mathrm{dL}$ ( $\geq 26.5 \mu \mathrm{mol} / \mathrm{L})$ within $48 \mathrm{~h}$; (2) an increase in serum creatinine to $\geq 1.5$ times baseline, which is known or presumed to have occurred within the prior 7 days; and (3) a urine volume $<0.5 \mathrm{~mL} / \mathrm{kg} / \mathrm{h}$ for $6 \mathrm{~h}^{12}$ 


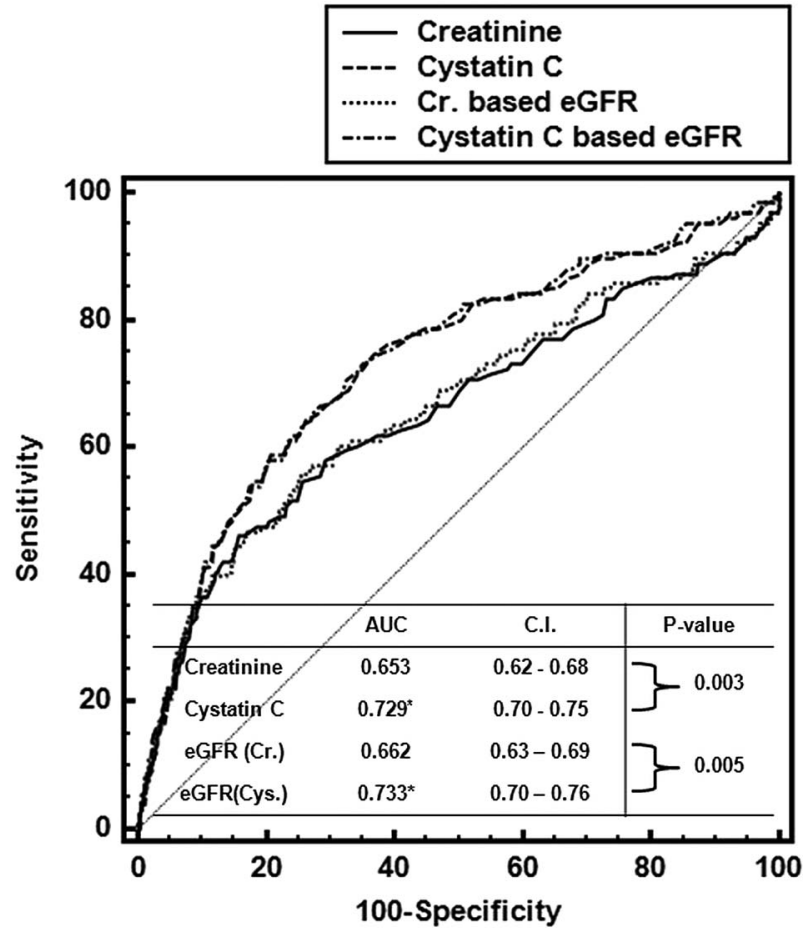

Figure 2 Area under the curve (AUC) comparison among cystatin $C$, creatinine, cystatin C-based estimated glomerular filtration rate (eGFR) and creatinine-based eGFR for renal dysfunction. Cystatin $C$ proved to be a more powerful predictor for postoperative renal complication than serum creatinine. We found that converting the eGFR produced a value more sensitive for predicting renal dysfunction. Both eGFR converted from the cystatin $C$ and creatinine increased the AUC value rather than pre-converting value, and of these two, the most sensitive predictor was the cystatin-based eGFR (AUC=0.733, Cl 0.70 to 0.760 ).

elimination pathway of cystatin C, its serum concentration has been used to estimate GFR in various experimental and clinical settings. ${ }^{16}$ Cystatin $\mathrm{C}$ can be measured from a spot serum sample and avoids the meticulous urine sample collections necessary for estimating creatinine clearance. Its assay is less susceptible to the methodological interference inherent in the routine method of creatinine estimation. In addition, cystatin $\mathrm{C}$ has less interindividual variation than serum creatinine, allowing for earlier detection of impairment in renal function. ${ }^{17}$ Therefore, if it is possible to take a sample of either from preoperative patients, sampling cystatin $\mathrm{C}$ would be more effective for predicting postoperative renal dysfunction or late surgical outcomes. In several recent studies, cystatin $\mathrm{C}$ has been suggested as an early indicator of impaired renal function and may be superior to serum creatinine in terms of diagnostic accuracy for reduced GFR. ${ }^{18-20}$ In addition, it has been reported to be a more sensitive marker of changes in GFR than serum creatinine. ${ }^{21}$

Serum cystatin $\mathrm{C}$ has been also shown to be more sensitive and specific than creatinine in a variety of clinical settings. ${ }^{16} 22$ A theoretical reduction in the incidence and severity of postoperative renal impairment has been proposed by eliminating factors related to the use of cardiopulmonary bypass, especially in high-risk patients, ${ }^{23}$ but the current evidence for off-pump surgery reducing postoperative renal dysfunction is conflicting. ${ }^{25}$

The evidence of the relationship between clinical outcomes of isolated OPCAB including renal impairment and serum cystatin $\mathrm{C}$ remains unknown, and it is also unclear which renal function assessment value (cystatin $\mathrm{C}$ vs creatinine) is more sensitive and specific for predicting renal dysfunction in OPCAB.

Therefore, we focused on clarifying the predictive power of serum cystatin $\mathrm{C}$ using discrete categories, and then comparing the ability of these discrete categories to the power of cystatin $\mathrm{C}$, creatinine and demographic factors for the prediction of clinical outcomes including renal dysfunction, mortality and MACCEs in OPCAB patients. Among the variables tested, age $(p<0.01)$ and high plasma cystatin $C(p=0.04)$ proved to be significant predictors for decreased mortality and MACCEs. For predicting renal dysfunction, cystatin C-based eGFR $(p=0.03)$ and serum cystatin $C$ serum level group $(p=0.01)$ were meaningful factors. We also looked for a cut-off value for cystatin $\mathrm{C}$ using receiver operating characteristic plotting and compared the predictive strength of the two renal function assessment values.
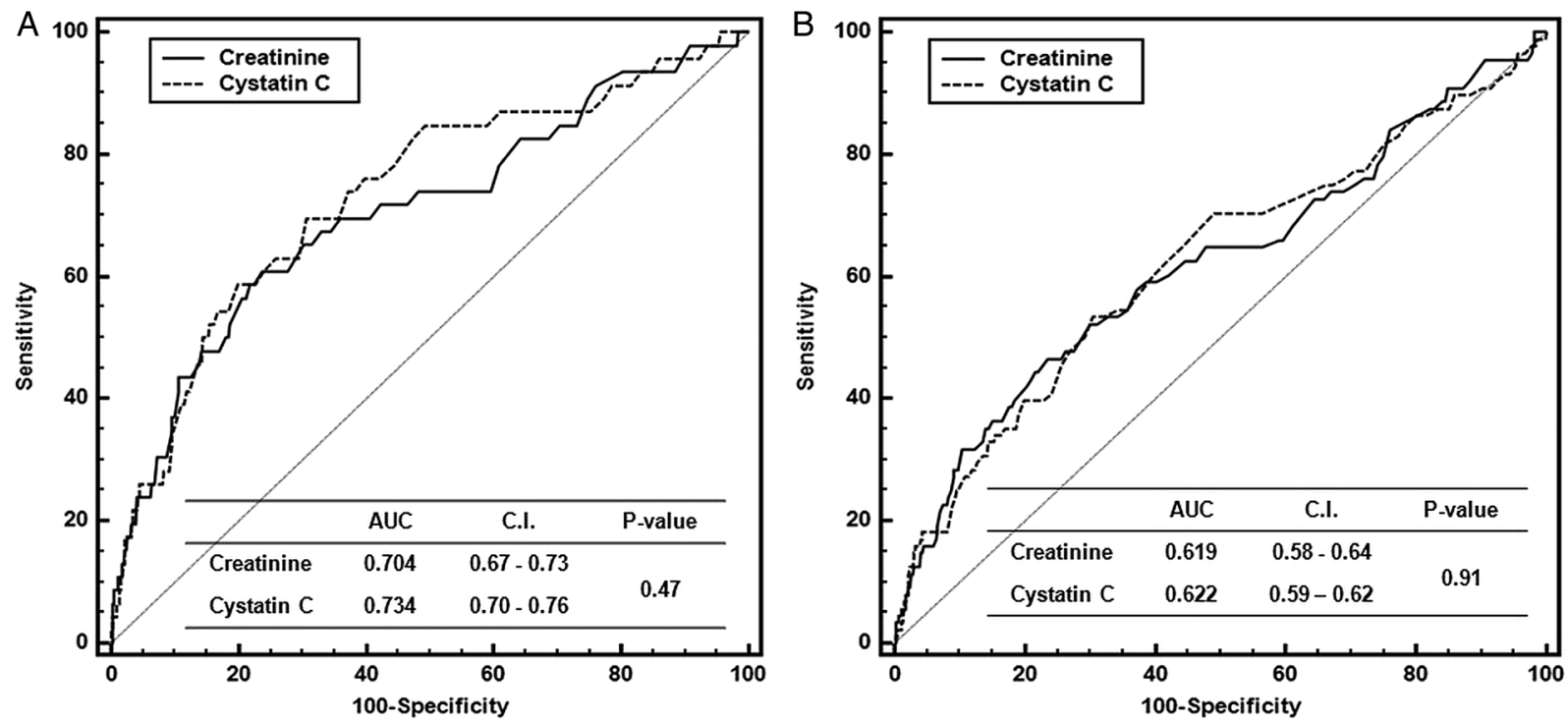

Figure 3 (A) Area under the curve (AUC) comparison between cystatin C and creatinine for mortality. (B) AUC comparison between cystatin C and creatinine for major adverse cerebrovascular and cardiovascular events (MACCEs). Follow-up duration was a mean of $35.2 \pm 18.1$ months (IQR 22.9-51.0 months). A MACCE was defined as the occurrence of death, non-fatal myocardial infarction, stroke and target vessel revascularisation. 

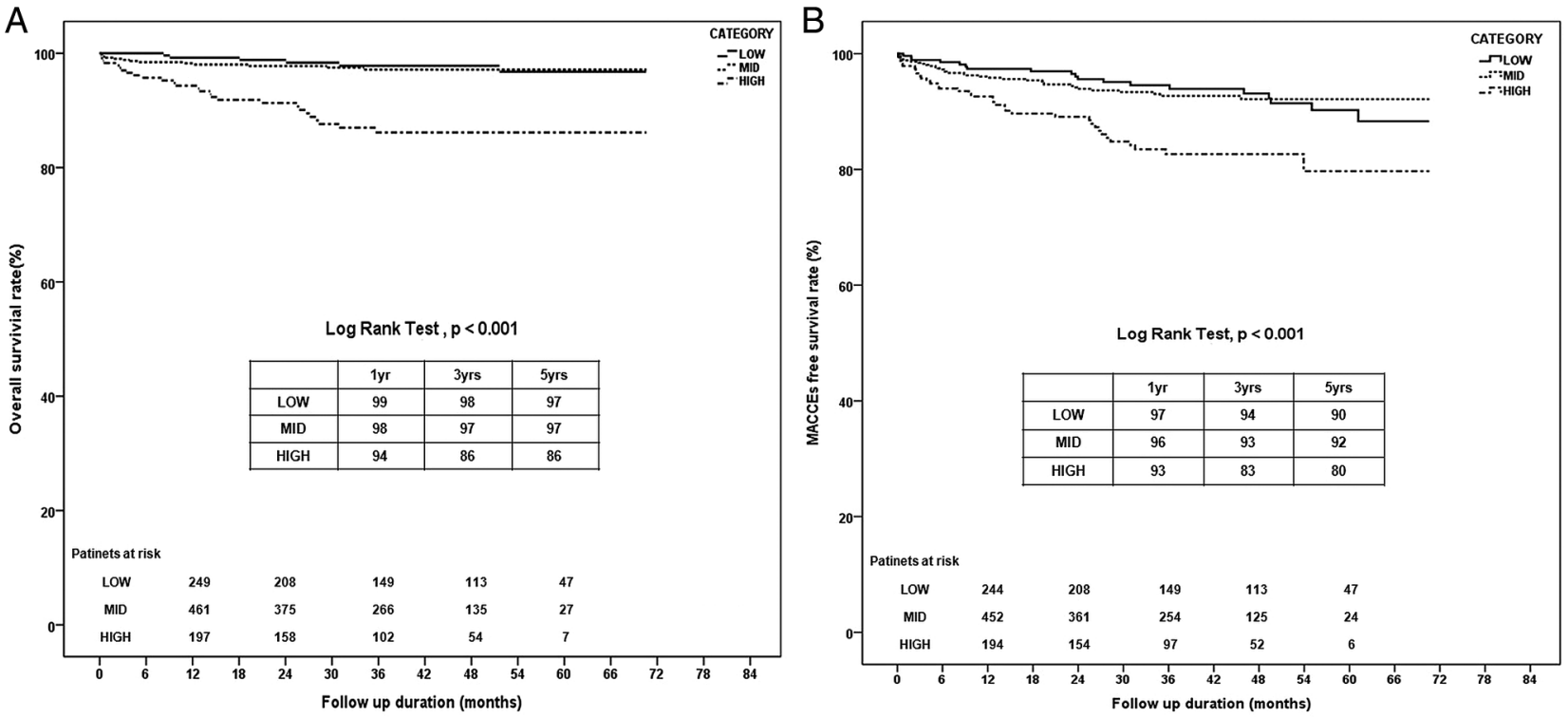

Figure 4 (A) Overall survival rate (\%) according to cystatin C level. (B) Free from major adverse cerebrovascular and cardiovascular events rate (\%) according to cystatin $C$ level. Category definitions: low: $0.83 \mathrm{mg} / \mathrm{L}$ >; mid: $0.83-1.13 \mathrm{mg} / \mathrm{L} ;$ high: $1.13 \mathrm{mg} / \mathrm{L}<$.

Receiver operating characteristic plots of serum cystatin C demonstrated that the AUC for renal dysfunction $(\mathrm{AUC}=0.73$, CI 0.70 to $0.75, \mathrm{p}<0.001)$ and for overall mortality (AUC $=0.73$, CI 0.70 to $0.76, \mathrm{p}<0.001$ ) were both statistically significant. The cut-off value for maximising AUC (or the Yoden index) of renal dysfunction was $1.04 \mathrm{mg} / \mathrm{L}$ (figure 1).

By definition, the group high had a cystatin $\mathrm{C}$ level of $>1.13 \mathrm{mg} / \mathrm{L}$, and the group's preoperative average creatinine level was $1.4 \pm 0.8 \mathrm{mmol} / \mathrm{L}$ (low group: $0.9 \pm 0.2$ and mid group: $1.0 \pm 0.2 ; \mathrm{F}$ value $=139, \mathrm{p}<0.001)$. However, this creatinine level was relatively lower than the level of creatinine generally known to be abnormal $(>1.5 \mathrm{mmol} / \mathrm{L})$. This gap between cystatin $\mathrm{C}$ and creatinine was probably a clue about the difference in their predictive power, so we compared the AUC value of each kidney assessment factor for renal dysfunction. We found that cystatin $\mathrm{C}$ showed a greater tendency to predict mortality

Table 3 Univariate and multivariate analysis for risk analysis of mortality and major adverse cerebrovascular and cardiovascular events (MACCEs)

\begin{tabular}{|c|c|c|c|c|c|c|c|c|}
\hline & \multicolumn{4}{|l|}{ Mortality } & \multicolumn{4}{|l|}{ MACCEs } \\
\hline & \multicolumn{2}{|l|}{ Univariate } & \multicolumn{2}{|l|}{ Multivariate } & \multicolumn{2}{|l|}{ Univariate } & \multicolumn{2}{|l|}{ Multivariate } \\
\hline & $\mathrm{HR}(95 \% \mathrm{Cl})$ & p Value & HR $(95 \% \mathrm{Cl})$ & p Value & $\mathrm{HR}(95 \% \mathrm{Cl})$ & p Value & $\mathrm{HR}(95 \% \mathrm{Cl})$ & p Value \\
\hline Age & 1.15 (1.09 to 1.21$)$ & 0.01 & $1.10(1.03$ to 1.17$)$ & 0.01 & 1.06 (1.03 to 1.08$)$ & 0.01 & 1.05 (1.01 to 1.08$)$ & 0.01 \\
\hline Female & 0.81 (0.43 to 1.53$)$ & 0.52 & & & 0.95 (0.60 to 1.51$)$ & 0.81 & & \\
\hline Weight & $0.98(0.95$ to 1.00$)$ & 0.09 & $0.99(0.96$ to 1.03$)$ & 0.84 & 0.99 (0.97 to 1.01$)$ & 0.28 & $0.98(0.95$ to 1.02$)$ & 0.35 \\
\hline DM & $0.78(0.44$ to 1.40$)$ & 0.40 & & & $1.15(0.75$ to 1.77$)$ & 0.52 & & \\
\hline Dyslipidemia & $0.42(0.21$ to 0.84$)$ & 0.01 & $0.44(0.21$ to 0.92$)$ & 0.03 & $1.18(0.76$ to 1.82$)$ & 0.46 & & \\
\hline Last creatinine & 1.96 (1.51 to 2.42$)$ & 0.01 & $1.40(0.82$ to 2.37$)$ & 0.22 & 1.59 (1.26 to 2.01$)$ & 0.01 & 1.41 (0.91 to 2.17$)$ & 0.13 \\
\hline Creatinine-based eGFR & $0.97(0.96$ to 0.98$)$ & 0.01 & $0.99(0.97$ to 1.02$)$ & 0.58 & 0.99 (0.98 to 0.99$)$ & 0.01 & $1.04(0.99$ to 1.09$)$ & 0.11 \\
\hline PAOD & $0.27(0.14$ to 0.53$)$ & 0.01 & 2.25 (1.08 to 4.70$)$ & 0.03 & $0.42(0.24$ to 0.73$)$ & 0.02 & $0.53(0.25$ to 1.12$)$ & 0.10 \\
\hline EurOSCORE & 1.08 (1.05 to 1.12$)$ & 0.01 & $1.0(0.93$ to 1.08$)$ & 0.92 & 1.06 (1.03 to 1.10$)$ & 0.01 & 1.01 (0.94 to 1.08$)$ & 0.84 \\
\hline $\mathrm{CHF}$ & 1.82 (0.56 to 5.89$)$ & 0.32 & & & 1.64 (0.59 to 4.54$)$ & 0.34 & & \\
\hline Arrhythmia & $1.69(0.52$ to 5.50$)$ & 0.38 & & & 2.51 (1.08 to 5.85$)$ & 0.03 & $0.37(0.14$ to 0.99$)$ & 0.37 \\
\hline NYHA (III $\leq)$ & $0.50(0.04$ to 6.86$)$ & 0.60 & & & 0.64 (0.06 to 7.05$)$ & 0.71 & & \\
\hline LVEF & $0.98(0.96$ to 1.0$)$ & 0.02 & $0.98(0.96$ to 1.00$)$ & 0.10 & $0.99(0.98$ to 1.00$)$ & 0.1 & & \\
\hline Distal anastomosis & 1.10 (0.78 to 1.54$)$ & 0.60 & & & 1.14 (0.84 to 1.56$)$ & 0.4 & & \\
\hline Pre. CK-MB & 0.99 (0.98 to 1.02$)$ & 0.90 & & & $1.00(0.99$ to 1.01$)$ & 0.71 & & \\
\hline Pre. cystatin C & $1.01(0.96$ to 1.07$)$ & 0.65 & & & $1.01(0.95$ to 1.07$)$ & 0.78 & & \\
\hline Cystatin C-based eGFR & $0.97(0.956$ to 0.980$)$ & 0.01 & $0.98(0.96$ to 1.01$)$ & 0.24 & 0.99 (0.98 to 0.99$)$ & 0.01 & $0.99(0.97$ to 1.00$)$ & 0.58 \\
\hline Group & & & & & & & & \\
\hline Mid vs low & $1.14(0.38$ to 3.48$)$ & 0.80 & $0.37(0.11$ to 1.24$)$ & 0.11 & 1.06 (0.44 to 2.55$)$ & 0.89 & $0.65(0.24$ to 1.75$)$ & 0.39 \\
\hline High vs low & $7.10(2.64$ to 19.12$)$ & 0.01 & $0.35(0.14$ to 0.83$)$ & 0.02 & 4.20 (1.86 to 9.46$)$ & 0.01 & $0.47(0.21$ to 1.03$)$ & 0.04 \\
\hline
\end{tabular}


Table 4 Multivariate Cox regression analysis for renal dysfunction

\begin{tabular}{|c|c|c|c|c|}
\hline & \multicolumn{4}{|l|}{ Renal dysfunction } \\
\hline & \multicolumn{2}{|l|}{ Univariate } & \multicolumn{2}{|l|}{ Multivariate } \\
\hline & HR $(95 \%$ Cl) & $p$ Value & HR $(95 \% \mathrm{Cl})$ & $p$ Value \\
\hline Age & 1.06 (1.03 to 1.08$)$ & 0.01 & 1.02 (0.99 to 1.05$)$ & 0.15 \\
\hline Female & 0.58 (0.41 to 0.83$)$ & 0.01 & 0.83 (0.50 to 1.39 ) & 0.48 \\
\hline Weight & 0.97 (0.96 to 0.99 ) & 0.01 & 1.00 (0.98 to 1.02 ) & 0.98 \\
\hline Smoker & 1.00 (0.71 to 1.42 ) & 0.99 & & \\
\hline DM & 0.53 (0.37 to 0.74$)$ & 0.01 & 0.63 (0.42 to 0.94 ) & 0.02 \\
\hline Dyslipidemia & 1.27 (0.88 to 1.82$)$ & 0.19 & & \\
\hline Last creatinine & 1.39 (1.15 to 1.69$)$ & 0.01 & 1.22 (0.82 to 1.82 ) & 0.34 \\
\hline $\begin{array}{l}\text { Creatinine-based } \\
\text { eGFR }\end{array}$ & 0.99 (0.98 to 0.99$)$ & 0.01 & 1.02 (1.01 to 1.03 ) & 0.01 \\
\hline COPD & 0.37 (0.18 to 0.74 ) & 0.01 & 0.71 (0.33 to 1.53 ) & 0.39 \\
\hline PAOD & $0.60(0.37$ to 0.99$)$ & 0.05 & 0.81 (0.46 to 1.43 ) & 0.46 \\
\hline EuroSCORE & 1.08 (1.05 to 1.12$)$ & 0.01 & 1.03 (0.98 to 1.09 ) & 0.26 \\
\hline NYHA $(3,4)$ & $0.50(0.04$ to 6.86$)$ & 0.6 & & \\
\hline LVEF & $0.99(0.97$ to 0.99$)$ & 0.01 & 1.01 (0.98 to 1.03 ) & 0.64 \\
\hline LVESD & 1.03 (1.01 to 1.05$)$ & 0.01 & 1.02 (0.98 to 1.07 ) & 0.29 \\
\hline $\begin{array}{l}\text { Distal } \\
\text { anastomosis }\end{array}$ & 0.99 (0.82 to 1.20$)$ & 0.93 & & \\
\hline Operation time & 1.00 (0.99 to 1.01$)$ & 0.76 & & \\
\hline Pre. cystatin C & 1.01 (0.98 to 1.04 ) & 0.04 & 0.96 (0.86 to 1.07 ) & 0.45 \\
\hline $\begin{array}{l}\text { Cystatin C-based } \\
\text { eGFR }\end{array}$ & 3.66 (2.79 to 4.80$)$ & 0.01 & 0.98 (0.96 to 0.99 ) & 0.03 \\
\hline \multicolumn{5}{|l|}{ Group } \\
\hline Low vs mid & $1.14(0.38$ to 3.48$)$ & 0.8 & 0.37 (0.11 to 1.24$)$ & 0.11 \\
\hline Low vs high & 7.10 (2.64 to 19.12 ) & 0.01 & 0.35 (0.14 to 0.83 ) & 0.02 \\
\hline
\end{tabular}

compared with creatinine (AUC 0.73 vs $0.65, p=0.003$ ) and renal dysfunction (AUC 0.80 vs 0.75 , CI -0.016 to 0.111 , $\mathrm{p}=0.15$ ), but the difference was not statistically significant. We also found that $1.05 \mathrm{mg} / \mathrm{L}$ of cystatin $\mathrm{C}$ was the cut-off value for maximising AUC (or the Yoden index) of mortality.

Wang et $a l^{26}$ demonstrated the potential usefulness of cystatin $\mathrm{C}$ as a test for detecting early changes of GFR in patients after coronary artery bypass grafting (CABG) ${ }^{26}$ As described in their previous studies, ${ }^{25} 27$ changes in the cystatin $\mathrm{C}$ concentration paralleled those of GFR. Of all the available markers, cystatin C had the best correlation with GFR. Cystatin C was more accurate and reflected the changes in GFR with greater sensitivity. ${ }^{21} 28$

Several other studies in various settings have determined that the cystatin $\mathrm{C}$ level has much strong associations with cardiovascular and other clinical outcomes in ambulatory patients. ${ }^{29} 30$ One recent study of 150 patients from three academic medical centres found that the cystatin $\mathrm{C}$ level was a stronger predictor of postsurgical renal dysfunction than was the creatinine level. The ability of cystatin $\mathrm{C}$ to predict renal dysfunction was correlated with its strong association with mortality, so the preoperative cystatin $\mathrm{C}$ level might be a prognostic factor for surgical clinical outcomes including mortality.

Despite several studies about the reno-protective effect of OPCAB, few studies have sought to determine the clinical correlation between cystatin $\mathrm{C}$ and OPCAB clinical outcomes including renal dysfunction. A prospective randomised comparison of 200 unselected patients undergoing off-pump versus conventional CABG reported no difference in the postoperative incidence of renal failure between the two groups. ${ }^{31}$ However, several large observational studies including a higher proportion of high-risk patients have reported a significant reduction in the frequency of renal failure in patients undergoing $\mathrm{OPCAB}^{24} 3233$ Based on these results, using the cystatin C check preoperatively, we might be able to anticipate renal dysfunction and prevent it by more aggressive postoperative intensive care management as well as predict surgical clinical outcomes. In our result using univariate and multivariate Cox regression analysis, high cystatin $\mathrm{C}(>1.15 \mathrm{mg} / \mathrm{L})$ was a significant risk factor for overall mortality and renal dysfunction. Therefore, cystatin $\mathrm{C}$ might be used not only to predict renal dysfunction but also to establish a mortality prognosis of isolated OPCAB patients.

\section{LIMITATIONS}

There were several limitations to this study. Our cohort of patients was not randomised, and the three groups were not precisely matched because of missing data. Adjustment for the differences among the three groups might be important to reduce bias in the estimates obtained (so we performed stratified analysis according to age category for minimising this bias; see online supplementary table). Another limitation was the relatively short follow-up period of just 35 months. A longer follow-up period may yield more results in terms of post-OPCAB mortality and morbidity, which in turn may help to further elucidate the role of cystatin $\mathrm{C}$ in predicting adverse cardiac events after OPCAB.

\section{CONCLUSIONS}

Cystatin $\mathrm{C}$ was a stronger predictor of renal dysfunction and mid-term mortality than serum creatinine. It was also a powerful predictor of the risk of MACCEs. Patients with a plasma cystatin $\mathrm{C}$ level $>1.13 \mathrm{mg} / \mathrm{L}$ seem to have an increased risk of mortality, MACCEs and postoperative renal dysfunction. Therefore, preoperative measurement of cystatin $\mathrm{C}$ has potential utility for risk stratification of renal dysfunction and might be an important predictor for the clinical outcomes following OPCAB.

\section{Key messages}

What is already known on this subject?

Until now, preoperative serum creatinine level was the strongest factor to predict a postoperative renal function status regardless of cardiac surgery types.

What might this study add?

In the present study, we found stronger prediction factor (cystatin C) for postoperative renal function status. Using this factor, we prevent postoperative renal dysfunction by adequate management before worsening of kidney.

How might this impact on clinical practice? In off-pump coronary artery bypass grafting surgery, postoperative renal function is strongly associated with late survival and clinical results. Therefore, we should prevent renal dysfunction before worsening of kidney status. From this predictive value (cystatin C), we prepare proper management of renal dysfunction.

Contributors SHL, Y-NY: Drafting the work or revising it critically for important intellectual content. SHL, Y-NY, HCC: Final approval of the version published. SHL, 
Y-NY, HCC, SL and K-JY: Substantial contributions to the conception or design of the work, or the acquisition, analysis or interpretation of data. Agreement to be accountable for all aspects of the work in ensuring that questions related to the accuracy or integrity of any part of the work are appropriately investigated and resolved.

Funding Yonsei University College of Medicine (grant number 6-2014-0011). Competing interests None declared.

Patient consent Individual patient consent was waived because this study did not interfere with patient treatment, and the database was designed so that individual patients could not be identified.

Ethics approval Institutional Review Board of Yonsei University College of Medicine.

Provenance and peer review Not commissioned; externally peer reviewed.

Open Access This is an Open Access article distributed in accordance with the Creative Commons Attribution Non Commercial (CC BY-NC 4.0) license, which permits others to distribute, remix, adapt, build upon this work non-commercially, and license their derivative works on different terms, provided the original work is properly cited and the use is non-commercial. See: http://creativecommons.org/ licenses/by-nc/4.0/

\section{REFERENCES}

1 Fortescue EB, Bates DW, Chertow GM. Predicting acute renal failure after coronary bypass surgery: cross-validation of two risk-stratification algorithms. Kidney Int 2000:57:2594-602.

2 Chertow GM, Lazarus JM, Christiansen CL, et al. Preoperative renal risk stratification. Circulation 1997;95:878-84.

3 Zanardo G, Michielon P, Paccagnella A, et al. Acute renal failure in the patient undergoing cardiac operation. Prevalence, mortality rate, and main risk factors. J Thorac Cardiovasc Surg 1994;107:1489-95.

4 Thakar CV, Arrigain S, Worley S, et al. A clinical score to predict acute renal failure after cardiac surgery. J Am Soc Nephrol 2005;16:162-8.

5 Wijeysundera DN, Karkouti K, Dupuis JY, et al. Derivation and validation of a simplified predictive index for renal replacement therapy after cardiac surgery. JAMA 2007:297:1801-9.

6 Levey AS, Bosch JP, Lewis JB, et al. A more accurate method to estimate glomerular filtration rate from serum creatinine: a new prediction equation. Modification of Diet in Renal Disease Study Group. Ann Intern Med 1999;130:461-70.

7 Herget-Rosenthal S, Trabold S, Pietruck F, et al. Cystatin C: efficacy as screening test for reduced glomerular filtration rate. Am J Nephrol 2000;20:97-102.

8 Newman DJ, Thakkar H, Edwards RG, et al. Serum cystatin C measured by automated immunoassay: a more sensitive marker of changes in GFR than serum creatinine. Kidney Int 1995:47:312-8.

9 Taglieri N, Fernandez-Berges DJ, Koenig W, et al. Plasma cystatin C for prediction of 1-year cardiac events in Mediterranean patients with non-ST elevation acute coronary syndrome. Atherosclerosis 2010;209:300-5.

10 Akerblom A, Wallentin L, Siegbahn A, et al. Cystatin C and estimated glomerular filtration rate as predictors for adverse outcome in patients with ST-elevation and non-ST-elevation acute coronary syndromes: results from the Platelet Inhibition and Patient Outcomes study. Clin Chem 2012;58:190-9.

11 Youn $\mathrm{Y}$-N, Shim $\mathrm{CY}$, Yang $\mathrm{H}$, et al. Effect of diastolic dysfunction on early outcomes during elective off-pump coronary artery bypass grafting: a prospective observationa study. Ann Thorac Surg 2011;92:587-93.

12 Levey AS, Levin A, Kellum JA. Definition and classification of kidney diseases. Am J Kidney Dis 2013;61:686-8.
13 Hobson CE, Yavas S, Segal MS, et al. Acute kidney injury is associated with increased long-term mortality after cardiothoracic surgery. Circulation 2009;119:2444-53.

14 Loef BG, Epema AH, Smilde TD, et al. Immediate postoperative renal function deterioration in cardiac surgical patients predicts in-hospital mortality and long-term survival. J Am Soc Nephrol 2005:16:195-200.

15 Kazama JJ, Kutsuwada K, Ataka K, et al. Serum cystatin C reliably detects renal dysfunction in patients with various renal diseases. Nephron 2002:91:13-20.

16 Tian S, Kusano E, Ohara T, et al. Cystatin C measurement and its practical use in patients with various renal diseases. Clin Nephrol 1997:48:104-8.

17 Page MK, Bukki J, Luppa P, et al. Clinical value of cystatin C determination. Clin Chim Acta 2000;297:67-72.

18 Orlando R, Mussap M, Plebani M, et al. Diagnostic value of plasma cystatin $\mathrm{C}$ as a glomerular filtration marker in decompensated liver cirrhosis. Clin Chem 2002;48(6 Pt 1):850-8.

19 Hoste EA, Damen J, Vanholder RC, et al. Assessment of renal function in recently admitted critically ill patients with normal serum creatinine. Nephrol Dial Transplant 2005;20:747-53

20 Westhuyzen J. Cystatin C: a promising marker and predictor of impaired renal function. Ann Clin Lab Sci 2006;36:387-94.

21 Randers E, Erlandsen EJ, Pedersen $\mathrm{OL}$, et al. Serum cystatin $\mathrm{C}$ as an endogenous parameter of the renal function in patients with normal to moderately impaired kidney function. Clin Nephrol 2000;54:203-9.

22 Mussap M, Dalla Vestra M, Fioretto P, et al. Cystatin C is a more sensitive marke than creatinine for the estimation of GFR in type 2 diabetic patients. Kidney Int 2002:61:1453-61.

23 Taggart DP, Westaby S. Neurological and cognitive disorders after coronary artery bypass grafting. Curr Opin Cardiol 2001:16:271-6.

24 Cleveland JC Jr., Shroyer AL, Chen AY, et al. Off-pump coronary artery bypass grafting decreases risk-adjusted mortality and morbidity. Ann Thorac Surg 2001;72:1282-8; discussion 88-9.

25 Abu-Omar Y, Mussa S, Naik MJ, et al. Evaluation of Cystatin C as a marker of renal injury following on-pump and off-pump coronary surgery. Eur J Cardiothorac Surg 2005;27:893-8.

26 Wang QP, Gu JW, Zhan XH, et al. Assessment of glomerular filtration rate by serum cystatin C in patients undergoing coronary artery bypass grafting. Ann Clin Biochem 2009:46(Pt 6):495-500.

27 Zhu J, Yin $\mathrm{R}$, Wu H, et al. Cystatin $\mathrm{C}$ as a reliable marker of renal function following heart valve replacement surgery with cardiopulmonary bypass. Clin Chim Acta 2006;374:116-21.

28 Le Bricon T, Thervet $\mathrm{E}$, Benlakehal $\mathrm{M}$, et al. Changes in plasma cystatin $\mathrm{C}$ after renal transplantation and acute rejection in adults. Clin Chem 1999;45:2243-9.

29 Shlipak MG, Coca SG, Wang Z, et al. Presurgical serum cystatin C and risk of acute kidney injury after cardiac surgery. Am J Kidney Dis 2011;58:366-73.

30 Shlipak MG, Katz R, Sarnak MJ, et al. Cystatin C and prognosis for cardiovascular and kidney outcomes in elderly persons without chronic kidney disease. Ann Intern Med 2006;145:237-46.

31 Puskas JD, Williams WH, Duke PG, et al. Off-pump coronary artery bypass grafting provides complete revascularization with reduced myocardial injury, transfusion requirements, and length of stay: a prospective randomized comparison of two hundred unselected patients undergoing off-pump versus conventional coronary artery bypass grafting. J Thorac Cardiovasc Surg 2003;125:797-808.

32 Magee MJ, Jablonski KA, Stamou SC, et al. Elimination of cardiopulmonary bypass improves early survival for multivessel coronary artery bypass patients. Ann Thorac Surg 2002:73:1196-202; discussion 202-3.

33 Cartier R. Off-pump surgery and chronic renal insufficiency. Ann Thorac Surg 2000:69:1995-6. 